\title{
La escena del miedo: posibilidad de una recepción aristotélica del terrorismo contemporáneo $^{1}$
}

\section{The Scene of Fear: Possibility of an Aristotelian Reception of Contemporary Terrorism}

Leopoldo Tillería Aqueveque ${ }^{2}$

\section{Resumen}

El artículo intenta, a contramano de la tradición, interpretar el fenómeno del miedo causado por el terrorismo contemporáneo, más que como un efecto político o sociológico, como una emoción esencialmente estética, vale decir, una sensación que se produce en nosotros una vez que nos hemos «representado» el incidente como una escena trágica. Metodológicamente, se han escogido cuatro acciones terroristas de este siglo en las que palmariamente se daría este «miedo estético», sobre todo por el papel trascendental en ellas de la tecnología: el 11/ 9, la toma del teatro Dubrovkade Moscú, la ejecución de rehenes por el Estado Islámico y la masacre de Christchurchen marzo pasado. Para ello, se sigue la interpretación de «miedo trágico» presentada por Aristóteles, particularmente en su Poética, y las formulaciones sobre el miedo entregadas por Kant y Burke, principalmente.

Palabras clave: Aristóteles; Miedo; Poética; Tecnología; Terrorismo

\begin{abstract}
The article attempts, contrary to tradition, to interpret the phenomenon of fear caused by contemporary terrorism, rather than as a political or sociological effect, as an essentially aesthetic emotion, that is, a sensation that is produced in us once we have «represented» the incident as a tragic scene. Methodologically, four terrorist actions of this century have been chosen in which this «aesthetic fear» would clearly occur, above all because of the transcendental role of technology in them: $9 / 11$, the seizure of the Dubrovkade theatre in Moscow, the execution of hostages by the Islamic State and the Christchurch massacre last March. For this, the interpretation of «tragic fear» presented by Aristotle is followed, particularly in his Poetics, and the formulations on fear given by Kant and Burke, mainly.
\end{abstract}

Keywords: Aristotle; Fear; Poetics; Technology; Terrorism.

\footnotetext{
${ }^{1}$ Trabajo recibido el 02/09/2019. Aceptado el 27/11/2019.

${ }^{2}$ Universidad Tecnológica de Chile. Contacto: leopoldo.tilleria@inacapmail.cl
} 


\section{Introducción}

Cada vez que somos testigos de algún acto terrorista que ocurre en alguna parte del mundo, y que ha sido «colgado» en cualquiera de los tantos medios tecnológicos disponibles para su difusión, parecen ocurrir dos cosas al mismo tiempo. Primero, creemos sentir un miedo o terror natural ante lo que estamos viendo u oyendo (ciertamente también respecto de las consecuencias que suponemos provendrán de eso que vemos u oímos). Segundo, caemos «envueltos» en esa historia de terror que tenemos ante nosotros: nos interesamos en su desarrollo, probablemente en sus detalles, nos llama la atención quién o quiénes están detrás de ella, el modus operandi, los mensajes o ultimátums que se puedan dar, hasta su performance, en fin, quedamos de algún modo, «atrapados» en la escena.

Pues bien, con cargo al a veces contradictorio concepto de miedo (phobos) formulado por Aristóteles en diversos lugares de su obra, quisiera sugerir que el terrorismo contemporáneo, puede ser interpretado básicamente dentro de la lógica de una escena de representación, a la que somos arrastrados a través de una sofisticada parafernalia de medios y acciones, que, a la larga, nos sumergen, querámoslo o no, en un estado de purificación esencialmente estética y no tanto política como pudiéramos suponer. En este cuadro, el miedo, como expresión del terrorismo global, se entiende - permítaseme la redundancia - sobre todo como un impacto sobre nuestra sensibilidad, antes que como una reacción políticamente más elaborada. Desde este punto de vista, y situándonos en el centro de una cierta «filosofía del miedo», digamos que nuestra tesis está justo al otro lado, por decir algo, de la consabida idea política de Hobbes de que «el Estado mismo se constituye por miedo».

El artículo se divide en tres partes: en la primera, abordaré el concepto de miedo en Aristóteles, en el que destacaré su alcance desarrollado en la Poética, y lo pondré en juego con otras interpretaciones teóricas que me parecen relevantes a este trabajo, como las de Kierkegaard y Kant. En la segunda, caracterizaré el fenómeno actual de globalización del terrorismo, y del miedo que genera, mediante la referencia a cuatro incidentes ocurridos este siglo y que me parecen suficientemente indicativos del panorama que quiero mostrar (seguramente la selección será discutible, pero, en fin, baste con decir que he procurado utilizar como criterio principal el del impacto mediático de dichas acciones). Asimismo, intentaré demostrar cómo en su esencia asoma o incluso predomina 
un sentido de escenificación, fundamentando esta presunción en la idea aristotélica de «miedo poético». Por último, concluiré con la tesis de quedicho resumidamente- el miedo que produce el terrorismo actual debiera ser visto, antes de como un fenómeno más bien político, como una escena - teatral o cinematográfica, da igual-a la que somos arrastrados en calidad de espectadores, y en torno a la cual las emociones que se desencadenan - el miedo especialmente- tendrían un componente estético fundamental.

\section{Eso del miedo}

Antes que Aristóteles, fue Homero, en La Ilíada, quien presentó en escena a Phobos (miedo o pavor), junto a su gemelo Deimos (pánico) y la diosa Enio (horror), como acompañantes de Ares en el campo de batalla. En todo caso, hay coincidencia en que el sentido que Homero da aquí al miedo es específicamente el de huida:

Phobos, en el griego primitivo, siempre comporta la idea de fuga, de huir aterrorizado de la batalla. La voz pasiva del verbo correspondiente, phobeisthai, significa «ser puesto en fuga», y es lo opuesto a bupomonein (del que procede hupomone), que significa «aguardar a pie firme», «soportar» (Barclay, 2002, p. 173).

A su vez, Aristóteles se refiere al miedo -con un sentido distinto al de Homero- en al menos tres lugares diferentes de su obra: en la Retórica, en la Ética Nicomaquea y en la Poética. Procuraré sintetizar estas tres definiciones, a pesar de que es en la Retórica donde el estagirita da del miedo una idea más acabada. En la Ética Nicomaquea lo define «como la expectación de un mal», ${ }^{3}$ es decir, como la inminencia -prácticamente la seguridad-de que algo malo nos puede suceder, y, en todo caso, pasajera y concreta respecto de esa amenaza que vislumbramos. En tanto, dice en la Retórica: «el miedo es un cierto pesar o turbación, nacidos de la imagen de que es inminente un mal destructivo o penoso (...), y ello además si no aparecen lejanos, sino próximos, de manera que estén, a punto de ocurrir». ${ }^{4}$ Aquí, la noción de imagen es muy relevante como fundamen-

${ }^{3}$ Aristóteles. Ética a Nicómaco .1115a 9.

${ }^{4}$ Aristóteles. Retórica. 1382a 21-26. 
to para este trabajo, en cuanto a que justamente es en el miedo -entendido retóricamente- donde «imaginamos» lo que nos podría sobrevenir como algo destructivo o penoso. O sea, sería una imagen mental.

Volviendo a la Ética Nicomaquea, Aristóteles, después de una serie de divagaciones, concluye que el miedo es en realidad una emoción, una páthe, junto a la ira, la venganza, la amistad y otras más. Esto es importante, porque llegar a establecer más o menos definitivamente que el miedo es, al mismo tiempo que una imagen mental, una emoción, nos coloca en la situación de que, en definitiva, el miedo también es una cuestión del cuerpo, del soma, vale decir, que tener miedo no solo es imaginarlo, sino en realidad vivirlo o, para ser más exactos, sentirlo.

Domínguez (2003) dice algo muy parecido:

Defino el «miedo» como una emoción más o menos pasajera queaparece cuando se presiente o supone un peligro real o aparente (esdecir, que "parece y no es») y concreto o inconcreto (vago, impreciso), que se puede sentir individual o colectivamente (p. 666).

Terminemos de comentar el sentido «ético» del miedo, no olvidando que lo que quiere decir Aristóteles -si entiendo bien- es que siendo el miedo una emoción natural, digamos, consustancial al hombre, el rango de virtuosismo ético de los hombres en relación a la forma de enfrentarlo, como emoción inherente a su naturaleza, a su physis, depende, como cada una de las situaciones concernientes a las virtudes aristotélicas, del tipo de virtud de que se trate. Así, por ejemplo, cuando Aristóteles habla de la virtud de la valentía, no dice que el hombre valiente es el que no tiene miedo (lo que entraría en colisión con la propia naturaleza del miedo), sino aquel que lo «administra» conforme a un rango intermedio de prudencia en el obrar: «El que lo rehúye todo y es temeroso y no aguanta nada se hace un cobarde; y el que no teme nada en absoluto, sino que se enfrenta a todo, temerario». ${ }^{5}$

En la Poética, en cambio, Aristóteles alude a la idea de phobos como vehículo de purificación. Ahí dice más o menos lo siguiente: que para que se trate de un poema de calidad (en este caso, de una «buena» tragedia), la obra deberá, ya sea mediante la estructura de sus acciones o mediante su espectáculo (esta noción de espectáculo es clave en la tesis que seguimos), inspirar temor o compasión en los espectadores, a tal

${ }^{5}$ Aristóteles. Ética a Nicómaco. 1104a 24-27. 
punto de provocar finalmente la catarsis, o, para decirlo como yo lo entiendo, una especie de limpieza o descarga emocional que se siente al haber experimentado en la obra las emociones de temor o compasión, tal «como si» hubiéramos sido nosotros los personajes de la tragedia. ${ }^{6}$ Sobre este punto, y tratando de no entrar en explicaciones demasiado complicadas, conviene oír a Umberto Eco, precisamente, acerca del carácter posible de este «estado de impacto» en que ha quedado el espectador luego de haber «sufrido» en primera persona el miedo o la compasión.

Escuchemos a Eco (2004):

Esta experiencia produce en nosotros una suerte de purificación, la catarsis, y no vamos a discutir ahora, reproduciendo un debate que ya ha durado siglos, si la purificación de que hablaba Aristóteles debía ocurrir de modo homeopático, -sufrimos las mismas pasiones del personaje, y al sufrirlas, nos vemos liberados- o de modo alopático -vemos representadas esas pasiones, pero al no estar personalmente implicados hasta el fondo, podemos, sí, liberarnos, pero no porque las compartamos, sino porque nos volvemos capaces de observarlas y juzgarlas a la debida distancia (p. 70).

Cualquiera sea la interpretación que tengamos de lo que Aristóteles quiere decir con catarsis, lo importante es que, en ambos casos, conforme a su esencia, nos «liberamos» de la posibilidad de «caer en desgracia», posibilidad que, de acuerdo a la trama, no tuvo el héroe trágico. Entonces, lo que de veras ocurre es que sentir ese miedo o compasión del que habla Aristóteles, nos avisa que, si hacemos tales y cuales cosas, podemos vernos en la misma situación trágica de los personajes del poema, o sea, pasar por sus mismas penurias y, por tanto, lo que hace es decirnos con toda claridad cómo comportarnos, es decir, qué hacer y qué no hacer si no queremos «en serio» sufrir lo que ha sufrido nuestro héroe. A esto es a lo que algunos han llamado «gozo inofensivo». Ahora, si alguien quiere ver en esto algo parecido a un fundamento político del «miedo poético», sea, con la salvedad de que mi objetivo no es hacer, por llamarlo así, una genealogía del miedo, sino, como he explicado, proponer una interpretación más bien estética del miedo asociado al terrorismo.

${ }^{6}$ Dice exactamente Aristóteles: «Y, puesto que el poeta debe proporcionar por la imitación el placer que nace de la compasión y del temor, es claro que esto hay que introducirlo en los hechos» (Aristóteles. Poética. 1543b 12-14). 
Otras dos recepciones que pueden inscribirse en este registro estético del miedo, son las del filósofo alemán Immanuel Kant y del filósofo danés Søren Kierkegaard. Kierkegaard, considerado el padre del existencialismo, es también reconocido como el filósofo de la subjetividad y de la angustia. En efecto, su referencia al miedo parece ubicarse justo en medio de un pensamiento tanto teológico como estético:

Sufre todo el dolor del héroe trágico, aniquila su alegría terrena, renuncia a todo, y es probable que en el mismo momento se cierre a sí mismo la posibilidad de alcanzar la exaltada alegría, tan preciosa para él, que habría estado dispuesto a comprarla a cualquier precio (Kierkegaard, 1997, p. 51).

Desde luego, el héroe de Kierkegaard es Abraham, quien «no renunció a Isaac por la fe; al contrario, lo obtuvo por ella». De aquí que, en realidad, temor y temblor representen el conflicto que Kierkegaard plantea entre la fe y la conciencia, puesto que solamente cuando el hombre se entrega a la mundanidad, olvidando su condición de ser dependiente de lo Absoluto, empieza, pues, a sentir un temor y temblor de las funestas e imprevisibles consecuencias que implica el designio divino (Calcín, 2017, p. 55). En otras palabras, el temor acomete al hombre cuando se aleja o niega al infinito, a Dios.

En Kant, en cambio, el miedo forma parte de lo sublime, sentimiento al que le dedica buena parte de su Crítica del juicio. Este «miedo sublime», esto «sublime dinámico», reconoce propiamente en la naturaleza el objeto de temor.

Dice Kant (2001):

Rocas audazmente colgadas y, por decirlo así, amenazadoras, nubes de tormenta que se amontonan en el cielo y se adelantan con rayos y con truenos, volcanes en todo su poder devastador, huracanes que van dejando tras sí la desolación, el océano sin límites rugiendo de ira, una cascada profunda en un río poderoso, etc., reducen nuestra facultad de resistir a una insignificante pequeñez, compara con su fuerza. Pero su aspecto es tanto más atractivo cuanto más temible, con tal de que nos encontremos nosotros en lugar seguro, y llamamos gustosos sublimes esos objetos porque elevan las facultades del alma por encima de su término medio ordinario y nos hacen descubrir en nosotros una facultad de resistencia de una especie totalmente distinta, que nos da valor para poder medirnos con el todo-poder aparente de la naturaleza (p. 204). 
En una palabra: miedo a la inmensidad. Lo sublime terrible hace violencia a la imaginación, la desconcierta, ya que esta no es capaz de comprender su objeto dado en un todo de intuición. Para Rubio (1991): «El cielo estrellado y la cúpula de San Pedro se deben ver como una gran bóveda 'que comprende todo' como la idea misma de infinito» (p. 41).Lo fundamental es, entonces, «representar la naturaleza dinámicamente sublime excitando el temor» (Delfín, 2013). Ahora, la inclusión de ambos filósofos pretende demostrar que el miedo, más allá de las interpretaciones psicológicas o sociológicas que se hayan dado -como la de Zygmunt Bauman, en torno a la relación entre miedo y globalización-, también ha sido abordado desde una tradición preferentemente estética.

\section{Underattack como evangelio}

Escogeré -espero lo menos arbitrariamente posible- cuatro momentos de nuestro siglo en que, siguiendo nuestra tesis, palmariamente el terrorismo ha querido impactar globalmente en sus objetivos. Veremos cómo el miedo en cada uno de estos casos, ha sido «administrado» convenientemente -incluso artísticamente-, como si siguiera un libreto perfecto.

Podemos situar en el 11/9 el momento exacto en que el terrorismo se mediatizó, o, siendo más precisos, se globalizó. No por nada Pierre Nora llama a este ataque un «acontecimiento monstruo». ${ }^{7}$ Nótese que no hay en esta conjetura ninguna pretensión ideológica en cuanto a discutir ni la identidad ni el origen de los autores o instigadores de estos atentados. Tampoco pretendo polemizar sobre la capacidad que tenía o no Al Qaeda de perpetrar los atentados en el 2001. Supongamos que fueron ellos. Lo cierto es que a partir de esta fecha el terrorismo ingresó a nuestros livings como si se tratara de alguien más de la familia. La posibilidad mediática que las cadenas internacionales aprovecharon extremadamente bien, supuso un punto de inflexión en la cobertura de los actos terroristas, que no se veía, por lo menos con el alcance visto de los extensísimos reportes de $\mathrm{CNN}, \mathrm{ABC}, \mathrm{NBC}$ y $\mathrm{CBS}$, desde los incidentes de Munich 1972 o Entebbe 1976. En efecto, si hubiera que organizar «técnicamente» los modos de divulgación más utilizados en estas trans-

\footnotetext{
${ }^{7}$ Cf. Nora, P., «Le retour de l'evénement». Le Goff, J. \& Nora, P. (dirs.), Faire de l'Histoire. Nouveauxproblèmes, Gallimard, 1974, pp. 210 y ss.
} 
misiones, uno tendría que decir que, por un lado, la televisión, y su reproducción instantánea en Internet, convierte el incidente en un verdadero reality con un despliegue que privilegia la extrema cercanía de las imágenes y un manejo más sofisticado de las velocidades de reproducción y, por otro, hace su aparición, con un éxito insospechado, especialmente en el campo del periodismo independiente, el uso más o menos sistemático del cameraman.

Pues bien, si hacemos caso a Aristóteles, en cuanto a que el miedo es una emoción que nunca dejamos de «padecer», que es propia de nuestra «alma» y que, de hecho, la mueve, debemos, como personas «con» miedo que somos, reconocer que lo que desató el 11/9 fue el tránsito desde nuestra somnolencia habitual a una vigilia obsesiva. Las escenas que pudimos ver en los medios muestran no solo una preparación ultra detallada de cada ataque o una creatividad que pensó incluso en los símbolos clave del «enemigo» (la marca World Trade Center por de pronto), sino que tecnológicamente dan cuenta de un despliegue nunca antes visto en materia de difusión de incidentes de este tipo. La frase underattack se impuso como marca informativa en la mayoría de los noticiarios, constituyéndose virtualmente en una suerte de evangelio mediático. Alineó a Occidente ante la «ofensiva islámica»: probabilísticamente todos podíamos ser blanco de los ataques. Desde el punto de vista de los atacantes parece no haber sido en absoluto fortuita la elección de la idea de los aviones como mecanismo de este terror global. ¿Se podría imaginar otra situación donde la amenaza (el «miedo ético» de Aristóteles) pudiera ser más inminente, y agreguemos, terrible, que un choque en avión y, por lo demás, donde la catástrofe se vea amplificada precisamente por «provenir del cielo»? Definitivamente no. Tanto así, que el propio cine de terror vio en los incidentes dell1/9 una posibilidad imperdible.

Dice Luis Pérez Ochando:

el 11 de septiembre no es un acontecimiento puntual, sino una metamorfosis cultural e ideológica, una reescritura de la mitología nacional cuya expresión resulta patente en el cine de terror. No en vano, el 11-S inaugurará la era del miedo, una era marcada por el temor a la otredad y por el deseo de infligir temor al otro, por el terror como estado social constante y por el terror como herramienta de control (cit. en Guillot, 2017). 


\section{El problema del héroe}

Un segundo incidente es la toma de rehenes del teatro Dubrovka de Moscú, entre el 23 y el 26 de octubre de 2002. Sin entrar en detalles políticos, religiosos o étnicos que no conciernen directamente a este escrito, digamos que estuvieron involucrados 922 rehenes en manos de 42 militantes chechenos armados, quienes reivindicaban su lealtad al movimiento separatista islamista en Chechenia. En realidad, pedían la salida de las tropas rusas de Chechenia. Como se sabe, la crisis termina con la operación de las fuerzas de seguridad rusas mediante la introducción de un agente químico secreto en los ductos de ventilación del teatro. Resultado: todos los terroristas y 129 rehenes muertos; una sola baja en los comandos rusos. Ahora, podrá parecer una anécdota que en medio de nuestra tesis del «miedo poético», este secuestro de produzca justo al inicio de una actuación en un teatro de Moscú. Pero escuchemos a Iosif Kobzon, negociador de la crisis en su primer momento: «Me empecé a dar cuenta que ingresaba en una escena de tragedia, llena de escombros, con disparos en las puertas; vi un cadáver tirado en la recepción, creo que era el cuerpo de la primera chica que mataron...» (Tria, 2013).

Aunque al inicio la toma del teatro no tuvo tecnologías asociadas a su difusión en directo (se trataba de un edificio cerrado y un espectáculo nocturno), podríamos decir, sin temor a equivocarnos, que el miedo invadió en esos cuatro días no solo a Moscú y a Rusia, sino que, en vivo, a todo el mundo. Las llamadas telefónicas de los rehenes a sus familiares y las grabaciones cámara en mano hechas por los propios terroristas en el interior del teatro parecen haber sido las únicas formas de divulgación de lo que ocurría, antes de la aparición en directo para la televisión de los jefes guerrilleros el día tres. Por supuesto, la negativa de Putin a negociar con los rebeldes aumentó dramáticamente los niveles de terror. Como sabemos, el desenlace ha sido hasta hoy objeto de controversia. Luego de que las fuerzas especiales tomaran por asalto el teatro (usando un gas mortífero y explosivos), un lugar común ha sido decir que fue una victoria militar (Putin no cedió un centímetro a las exigencias chechenas y no sobrevivió ningún rebelde), pero una tremenda derrota desde el punto de vista humanitario, con 130 rehenes muertos en la «operación de rescate». Los más críticos dirán que a Putin, como buen ex KGB, poco le importaron nunca los rehenes.

Como sea, la fisonomía del miedo se da acá de una forma muy peculiar. Efectivamente, si seguimos la Poética, notaremos que el miedo, 
de una forma u otra, se relaciona con la noción de héroe, en el sentido de que, aunque en la tragedia no sea lo primero -lo primero es, dice Aristóteles, la trama de la historia- «es indispensable su participación, pues de él emanan tanto el pensamiento que acompaña siempre a la acción, como el carácter, el cual, aunque de valor indirecto es el resorte por el que se manifiesta la acción» (Aspé, 2010, p. 12).Y la acción, como ya hemos dicho, debe mover a miedo o compasión. Ahora bien, en el caso que estamos viendo, y cualquiera sea la índole de las motivaciones que hicieron que los hechos siguieran tal dirección y no otra, la escena del teatro de Moscú parece un montaje deliberado para conseguir determinados fines, entre ellos, transmitir miedo a buena parte de la comunidad internacional. $\mathrm{Y}$ aquí quisiera insistir en que justamente el miedo parece aflorar, no tanto de suponer, por decirlo de algún modo, que por no estar de acuerdo con el separatismo checheno o por asistir a un espectáculo en el centro de la capital de la potencia invasora, puedo ser secuestrado por un comando de chechenos repleto de explosivos (o sea, la sola idea política), sino, de verdad, de observar o imaginarme (recordemos la definición «retórica» de miedo) las condiciones humanas en que se está desarrollando el secuestro, vale decir, la «escena trágica» propiamente tal.

Quiénes fueron o pudieron ser los héroes del teatro de Moscú es un asunto que no vamos a decidir acá. Lo que importa es convenir que esta tragedia, trátese del observador que se trate, siempre contó con un héroe que le diera sentido. Para algunos - con toda seguridad los máslos héroes fueron los centenares de rehenes ajenos al conflicto; para otros, habrán sido las tropas de élite, que arriesgaron sus vidas por su patria y ante un enemigo al que poco le importaba saltar en pedazos; y para otros, en cambio, los héroes palmariamente fueron los guerreros chechenos, que dieron sus vidas por su tierra, por sus familias y por su fe, a sabiendas de que no tenían ninguna probabilidad de sobrevivir. La noción de héroe, en cualquier caso, parece funcionar, siguiendo el patrón estético de Aristóteles, como una idea genérica que viene a otorgar un trasfondo argumental a los hechos. Por cierto, quienes estuvieron tras los acontecimientos de Moscú posicionaron en los medios una historia creíble, paradójicamente, por lo improbable que resultaba que más de 900 personas fueran tomadas como rehenes por un número muy inferior de secuestradores, pero, ante todo, por las inhumanas condiciones del cautiverio. En razón de esto, bien podría argumentarse que el miedo fue administrado «dramáticamente», no solo por los propios jefes che- 
chenos o por el mando político ruso, sino, dicho desde una postura políticamente incorrecta, por los mismos medios de comunicación.

\section{Miedo como sistema}

Una tercera experiencia, con seguridad la más cruda de todas, mirado desde lo que me atrevo a llamar «miedo sobrecogedor», es la práctica del autodenominado Estado Islámico (EI) de colgar en Internet con lujo de detalles, como ha quedado claro- los rituales de eliminación de quienes han tenido la desgracia de ser capturados bajo el rótulo de infieles y enemigos de su fe. Con un uso de los medios que incluso llega a lo espeluznante, EI -uno de los grupos terroristas más ricos de la historia- logró montar un diseño de imagen en sus ejecuciones que no le va en zaga a ninguno de los modernos directores de cine gore. Primeros planos, cuidadas ediciones y montajes y hasta imágenes ralentizadas son parte de la tecnología usada para registrar el sinnúmero de barbaridades cometidas en contra de personas atadas de manos y, no sabemos si afortunadamente o no, presuntamente sedadas. Sin entrar en detalles, digamos que estamos hablando, en este caso, de un miedo palmario y concreto, asociado sobre todo a la idea de extrema crueldad de los ejecutores, idea que se incrementa sabiendo que hay cientos de rehenes que pueden ser eliminados en cualquier momento. Como es obvio, el efecto inmediato apuntó a los territorios que EI comunicó serían parte de su califato antes del 2020. El mensaje es más o menos este: los ajusticiamientos en nombre de Dios que ustedes ven en estas imágenes, seguirán ocurriéndole a todos quienes no se sometan a nuestra autoridad, y, por supuesto, no se conviertan a nuestra religión. Sed fieles y se os perdonará la vida.

Sin embargo, el impacto fue tal, que el «asunto EI» llegó a ser prioridad en la agenda internacional de muchos países del mundo, empezando por la llamada «coalición», más allá de que hoy se diga que el proyecto integrista de EI fracasó desde el punto de vista geopolítico, tras la recuperación aliada(gracias, en buena parte, a la resistencia kurda) de varias zonas de control e influencia que estaban en manos de EI. Ahora bien, si hubiera que describir en una palabra su efecto se diría que miedo parece ser la más indicada. Por varias razones. No solo por una especie de repugnancia natural y yo diría, también, por una suerte de tristeza que sentimos ante la crueldad de las ejecuciones que hemos visto (imaginamos aquellas que no hemos visto), sino también porque nos represen- 
tamos, incluso si estamos convencidos de que se trata de un pensamiento irracional, el sufrimiento o, para decirlo en términos trágicos, el padecimiento y la agonía a que seríamos sometidos en caso de ser nosotros los ejecutados. Un segundo «tipo» de miedo pareciera tener que ver con el concepto de «zona de control total», que es parte de la propaganda que EI se ha encargado de reproducir de modo sistemático. Claro, el que un determinado territorio caiga bajo control del grupo (estamos suponiendo el caso, obviamente, de quienes no comulguen con su religión o ideología, que no es el de los cientos de militantes de distintos países que se han enrolado voluntariamente en sus filas), implica no solo la posibilidad de perder la propia vida, sino la de quedar sometido normativamente a las prácticas religiosas, económicas y políticas de un régimen fundamentalista (ni hablar de la posibilidad de ser esclavo sexual).La escena representada, siguiendo a Aristóteles, parece «movernos a temor y compasión» al mismo tiempo.

\section{Miedo online}

Por último, y más cercano en el tiempo, creo necesario incluir un episodio que marca, en mi opinión, un punto de inflexión en cuanto a lo que hemos llamado «administración del miedo y terrorismo». Hablo de la masacre de 51 fieles musulmanes en las mezquitas de Nueva Zelanda en marzo recién pasado. Tuve la posibilidad de ver de manera diferida la «transmisión» que registró la cámara Gopro del casco del terrorista que entró a la Mezquita de Al Noor y puedo asegurar que las cuotas de miedo de las víctimas escalan indistintamente hacia los estados de desesperación, pánico o colapso. Me centraré en el manejo del miedo por parte del terrorista -concediendo la tesis del «atacante solitario»- y no en las condiciones sociológicas, psicológicas o políticas que pudieran explicar su ataque (por ejemplo, el asunto del manifiesto ideológico que minutos antes colgó en la red o si su extremismo de derecha pudiera ser entendido como una respuesta individual al fundamentalismo musulmán).

Lo fundamental acá es la señal en vivo de los ataques (transmitidos en tiempo real por Facebook Live), cuestión que enseguida determina una escena completamente diferente a las anteriores. Pero, ¿qué es lo nuevo? En primer lugar, la posibilidad de que millones de usuarios de redes sociales vean en directo (virtualmente como si se tratara de una jugada de Free Fire o Fortnite) cómo una a una las víctimas iban siendo 
eliminadas por el «jugador-terrorista». Esto da, en primera instancia, una dimensión moralmente muy controversial a la transmisión, en el sentido de que las personas que veían en vivo la secuencia, probablemente hayan «decidido» quedarse mirando la matanza, pudiendo no hacerlo, justamente porque el miedo, como emoción primaria que se siente al considerar inminente una amenaza o peligro, parece haber dado lugar más bien a otro tipos de emociones, como por ejemplo, la del placer del juego o, en el mejor de los casos, la de curiosidad (siguiendo la lógica de un noticiario hiperrealista), pero poco o nada cercano a un «miedo primario». Parafraseando a Baudrillard, se diría que lo que se ve acá es una suerte de seducción límite, en términos de que lo que se administra es algo así como una pornografía de la muerte, en la que mientras más detallada sea la imagen y más cómodo el lugar donde estemos, mejor evaluaremos la estética del mensaje o, en otras palabras, mejores voyeristas seremos.

\section{Conclusión}

A partir de lo dicho, quisiera sugerir algunas ideas que pudieran cerrar la argumentación que he venido desarrollando sobre la controvertida relación entre miedo y terrorismo:

1. La posibilidad de interpretar el miedo causado por el terrorismo actual -en principio un miedo exclusivamente político, o sociológico, si se quiere- más bien como un «miedo esencialmente estético», producido en medio de una escena preparada con lujo de detalles y respecto de la cual -como debiera ocurrir en las «buenas» tragedias, a decir de Aristóteles- tendemos a desarrollar una especie de purificación de nuestros propios miedos, sobre todo tratándose de una trama bien conocida por todos a partir del 11/9.

Tal como señala Pincheira (2010):

El miedo que provocó el atentado a las Torres Gemelas, le habría devuelto a los Estados Unidos la claridad de que el mal existe, e hizo posible nuevamente la acción. El 11 de septiembre no fue el fin de la historia; al igual que el temor salvador de Adán y Eva, significó nada más que el principio (p. 577).

2. El impacto de estas acciones pareciera responder a una lógica de «administración del miedo», donde lo que se administra es principalmente 
la sensibilidad de los espectadores, por medio de un «espectáculo» que diríamos con Baudrillard- nos deja atrapados en la hiperrealidad (la transmisión en vivo de la masacre de Christchurch «desde dentro» es el mejor ejemplo). Sin embargo, no quiero dejar de referirme a la censura que sobre algunas de estas «escenas» han ejercido tanto el establishment político como los propios medios. Hay decenas de fotografías de personas lanzándose al vacío desde las Torres Gemelas, luego de que estas empezaran a incendiarse el 11/9. Tales imágenes han sido un verdadero tabú no solo para los medios, sino para la sociedad estadounidense en general, tanto así, que ni siquiera el número final de personas que saltaron ha sido confirmado por las autoridades. Ni hablar de sus identidades. Desde luego, no es precisamente la falta de detalles de esas imágenes o la imposibilidad de representarnos la situación límite a la que estas personas se vieron enfrentadas lo que determinó que se haya decidido no mostrarlas (el argumento oficial es que mostrar estas imágenes violaría la privacidad de los fallecidos). La razón más segura, creo yo, es que, frente a la amenaza islámica, que desde ese día se convirtió en el leitmotiv de Occidente, se haya preferido mostrar al mundo el rostro del «héroe americano» (bomberos, policías, rescatistas), levantando desde el día uno la ciudad derrumbada, y no la cara probablemente más triste y desoladora representada por quienes se vieron forzados a «tomar una decisión imposible».

3. De acuerdo a la idea de miedo descrita por Aristóteles en su Poética, es decir, el miedo como instrumento de purgación o purificación, que debiera advertirnos sobre qué hacer y qué no hacer para no sufrir «de verdad» los infortunios de los personajes, el impacto mediático del terrorismo contemporáneo, antes de como un fenómeno estrictamente político, cabe entenderse como una escena donde el concepto de héroe es fundamental para que podamos no necesariamente identificarnos con él, sino desarrollar «en serio», ante la evidencia de su tragedia, el miedo como factor de identificación ante una amenaza que creemos posible. En los casos que vimos, los ciudadanos de Manhattan, los asistentes al teatro Dubrovka, los prisioneros de EI y los fieles musulmanes de Christchurch, parecen reunir con claridad esa condición.

4. Por último, en un sentido propiamente filosófico, y siguiendo los desarrollos de los empiristas Locke y Burke, digamos que el miedo, más allá de que la tradición lo haya considerado la «bestia negra» de las emocio- 
nes, antes que paralizarnos o concientizarnos o domesticarnos, como muchos han señalado, parece, de verdad, cautivarnos. Esta posibilidad de salirnos de la interpretación común de un «miedo político» tras la acción terrorista, nos libera no solo de una idea un poco forzada de «rebaño pasivo», víctima de un miedo, por decirlo así, institucionalizado (el retumbe histórico del terror político administrado por la Revolución Francesa). ${ }^{8}$ A contramano, dice Locke: «una ligera sensación quemante -como el miedo- nos impulsa más poderosamente de lo que nos atrae o cautiva la perspectiva de grandes placeres» (cit. en Robin, 2018, p. 14).

Pero quisiera concluir con las palabras del filósofo Edmund Burke, que posiblemente resuman en su totalidad el sentido de este trabajo, y nos acerquen a lo que podría denominarse, como concepto final, una estética del terrorismo:

No obstante, si justo en el momento en que los espectadores están en el punto más elevado de sus expectativas «son informados de que un criminal de alto rango está a punto de ser ejecutado en la plaza contigua, en un momento el teatro queda vacío, lo que demuestra la debilidad comparativa de las artes de imitación, y la proclamación del triunfo de la verdadera compasión» (cit. en Delfín, 2012).

\section{Referencias bibliográficas}

Aristóteles. (1974). Póetica. Edición de Valentín García Yebra. Madrid, España: Gredos.

Aristóteles. (2005). Ética a Nicómaco. Madrid, España: Alianza

Aristóteles. (2000). Retórica. Madrid, España: Gredos.

Aspé, V. (2010). El concepto de héroe trágico en la Poética de Aristóteles. Philosophia, 11-24. Recuperado de https://tinyurl.com/y3rq9tjk

Barclay, W. (2002). Palabras griegas del Nuevo Testamento. Texas, Estados Unidos: Casa Bautista de Publicaciones.

Calcín. E. (2017). El temor y la angustia en Søren Kierkegaard. Phainomenon, 16 (1), 49-55. Recuperado de https://tinyurl.com/y5syxb7h

Delfín, O. (2012). Burke Edmund: el sentimiento de terror, del dolor y el placer. Recuperado de https://tinyurl.com/yxsaxuq7

\footnotetext{
${ }^{8}$ Aquí estaría también, aunque en una dirección opuesta, la idea epicúrea, encarnada en la figura del terrorista, de que a la muerte no se le debe temer.
} 
Delfín, O. (2013). Kant Immanuel: de lo sublime dinámico. Recuperado de https://tinyurl.com/y5x8wos4

Domínguez, V. (2003). El miedo en Aristóteles. Psicothema, 15 (4), 662 666. Recuperado de https://tinyurl.com/y3vncuyy

Eco, U. (2004). Aristóteles entre Averroes y Borges. Variaciones Borges (17), 65-85. Recuperado de https://tinyurl.com/yyeov9f7

Guillot, E. (2017). El terror que surgió de las Torres gemelas. Recuperado de https://tinyurl.com/y3zvh39k

Kant. I. (2001). Critica del juicio. Madrid, España: Espasa.

Kierkegaard, S. (1997). Temor y temblor. Barcelona, España: Altaya.

Pincheira, I. (2010). El miedo. Historia de una idea política. Corey Robin. Polis, 9 (25), 577-581. Recuperado de https://tinyurl.com/ y67n7kas

Robin, C. (2018). El miedo. Historia de una idea politica. México, México: FCE.

Rubio, J. (1991). Lo sublime. Universitas Philosophica, 9 (17-18), 37-49. Recuperado de https://tinyurl.com/y2eockch

Tria, C. (18 de octubre de 2013). Rehenes en Moscú [Archivo de video]. Recuperado de https://tinyurl.com/y4np3gzc 